\title{
INEQUALITIES FOR AVERAGES OF DIVIDED DIFFERENCES
}

\author{
A. M. FINK
}

Abstract. We provide upper bounds for the averages of divided differences in terms of the norms of an appropriate derivative. These generalize a result of Ostrowski.

Mathematics subject classification (1991): 26D10.

Key words and phrases: Ostrowski, divided differences, averages.

\section{REFERENCES}

[1] Ostrowski, A.M., On some Integral Inequalities II, Basel Mathematical Notes 24 (1965), 1-11.

[2] FinK, A.M., Crinkled functions and Intersections with Polynomials, Proc. Amer. Math. Soc. 118 (1993), 797-800.

[3] Schoenderg, I.J., Cardinal Spline Interpolation, Regional Conference Series in Applied Mathematics, SIAM, 1973.

[4] FINK, A.M., Conjugate Inequalities for Functions and Their Derivatives, SIAM Jour. Anal. 5 (1974), $399-411$.

[5] FinK, A.M. AND Jodeit, MAX JR., Jensen Inequalities for Functions with Higher Monotonicities, Aeq. Math 49 (1990), 26-43. 